\title{
CREB selectively controls learning-induced structural remodeling of neurons
}

\author{
Silvia Middei, ${ }^{1,2,10}$ Alida Spalloni, ${ }^{3}$ Patrizia Longone, ${ }^{3}$ Christopher Pittenger, ${ }^{4}$ \\ Shane M. O'Mara, ${ }^{7}$ Hélène Marie, ${ }^{8,9}$ and Martine Ammassari-Teule ${ }^{1,2,10}$ \\ ${ }^{1}$ CNR-National Research Council, Rome 00143, Italy; ${ }^{2}$ Experimental Neurology Unit, ${ }^{3}$ Molecular Neurobiology Unit, Santa Lucia \\ Foundation, Rome 00143, Italy; ${ }^{4}$ Department of Psychiatry and Psychology, ${ }^{5}$ Yale Child Study Center, and ${ }^{6}$ Interdepartmental \\ Neuroscience Program, Yale University, New Haven, Connecticut 06508, USA; ${ }^{7}$ Trinity College Institute of Neuroscience, Trinity \\ College Dublin, Dublin 2, Ireland; ${ }^{8}$ Laboratory of Molecular Mechanisms of Synaptic Plasticity, European Brain Research Institute, \\ Rome 00143, Italy
}

\begin{abstract}
The modulation of synaptic strength associated with learning is post-synaptically regulated by changes in density and shape of dendritic spines. The transcription factor CREB (cAMP response element binding protein) is required for memory formation and in vitro dendritic spine rearrangements, but its role in learning-induced remodeling of neurons remains elusive. Using transgenic mice conditionally expressing a dominant-negative CREB (CREBS133A: mCREB) mutant, we found that inhibiting CREB function does not alter spine density, spine morphology, and levels of polymerized actin in naive CA1 neurons. CREB inhibition, however, impaired contextual fear conditioning and produced a learning-induced collapse of spines associated with a blockade of learning-dependent increase in actin polymerization. Blocking mCREB expression with doxycycline rescued memory and restored a normal pattern of learning-induced spines, demonstrating that CREB controls structural adaptations of neurons selectively involved in memory formation.
\end{abstract}

[Supplemental material is available for this article.]

The occurrence of learning depends on specific modifications in the strength and number of synaptic connections. The persistence of those changes, which are mediated by structural reorganization of neuronal circuits in brain regions critical for specific forms of acquisition, supports the persistence of memory (Lamprecht and LeDoux 2004). Dendritic spines, the post-synaptic sites of excitatory synapses, are the main loci for this structural reorganization, and, consistently, numerous studies reported an increase in spine density following memory formation (O'Malley et al. 1998; Leuner et al. 2003; Knafo et al. 2004; Restivo et al. 2006, 2009a). Repeated visualizations of dendritic spines in living rodents have then clarified that learning elicits a dual process of spine formation and spine elimination, and that the net increase in spines observed upon training results from an imbalance in favor of spine formation (Xu et al. 2009; Yang et al. 2009).

The transcription factor cAMP response element binding protein (CREB) is a key molecule involved in memory formation (Barco and Marie 2011), and enhancing the function of the transcription factor CREB in CA1 pyramidal neurons increases hippocampus-dependent memory (Restivo et al. 2009b; Sekeres et al. 2010; Suzuki et al. 2011). Surprisingly, while in vitro studies have shown that acute manipulations of CREB activity regulates changes in spine number and shape in mammals (Murphy and Segal 1997; Segal and Murphy 1998; Marie et al. 2005), the involvement of CREB-dependent transcription in learning-dependent structural remodeling remains unexplored.

\footnotetext{
9Present address: IPMC_CNRS/UNSA UMR 7275, 06560 Valbonne, France

${ }^{10}$ Corresponding authors

E-mail s.middei@hsantalucia.it

E-mail martine.teule@cnr.it

Article is online at http://www.learnmem.org/cgi/doi/10.1101//m.025817.112.
}

To investigate this point, we used mice conditionally expressing a dominant-negative CREB mutant (CREBS133A, referred hereafter as mCREB mice) (Newton et al. 2002). The presence of mCREB mutation reduces CREB-mediated gene transcription by occlusion of CRE sites (Carlezon et al. 2005) and alters fear memory consolidation (Tronson et al. 2012). We report that, in the naive mice, chronic CREB inhibition does not affect spine density, spine morphology, and levels of polymerized actin in CA1 neurons. CREB inhibition, however, impairs contextual fear conditioning (CFC) and induces CFC-evoked decreases in spines and blockade of actin polymerization. Doxycycline treatment reverts CFC impairment and CFC-induced spine loss. The observation that hippocampal connectivity is intact in naive mCREB mice but collapses in trained mCREB mice provides the first evidence that CREB selectively controls learning-induced structural remodeling of neurons.

\section{Results}

\section{Neuronal localization of mCREB}

Adult mCREB bitransgenic mice (Newton et al. 2002) and wildtype (WT) littermates were evaluated for hippocampal mCREB expression. To avoid potential developmental defects due to the presence of the transgene, mCREB expression was prevented during late pregnancy and until weaning by doxycycline (doxy) administration and then activated for several weeks after weaning by doxy removal. mCREB expression was visualized by immunohistochemical detection of the Flag tag, which labels neurons expressing the transgene. Flag-mCREB immunoreactivity was evident in forebrain regions including the hippocampus and restricted to the cell body layers (Fig. 1A). This pattern indicates 
A



WT



WT

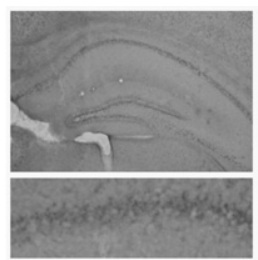

mCREB off doxy

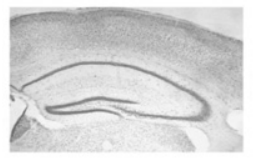

MCREB

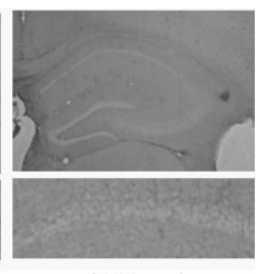

mCREB on doxy

Figure 1. mCREB expression and hippocampal structure analysis in bitransgenic mice. (A) Patterns of MCREB expression in bitransgenic mice visualized by the immunofluorescent detection of the Flag tag, which labels cell bodies of neurons expressing the transgene. (Left panel) No Flag expression was detected in WT mice. (Middle panel) Flag expression was observed in the CA1 field of the hippocampus of adult mCREB mice off doxycycline. (Right panel) Doxycycline (40 mg/ $\mathrm{kg}$ in food) treatment for $10 \mathrm{~d}$ abolished transgene expression because no Flag immunoreactivity was evident in mCREB doxycycline-treated mice. (B) Nissl staining of hippocampi of adult WT and MCREB after chronic (6 wk) mCREB expression. Nissl staining of the hippocampus of WT (left) and mCREB (middle) mice; magnification $4 \times$ showing no brain structure alteration.

specific neuronal expression, suggesting suppression of CREBdriven transcription in CA1 cells, in the absence of doxy. No Flag-tag immunoreactivity was detected in WT mice or in mCREB mice after $10 \mathrm{~d}$ of doxy treatment (Fig. 1A), thus confirming the effectiveness of the doxy-dependent regulation of mCREB expression in our model. To check for possible abnormalities in the hippocampal structure after chronic mCREB expression during adulthood, slices of naive (i.e., mice that never left their home cage) mCREB and WT mice were stained with Nissl (Fig. 1B). No anatomical alterations of the hippocampus were evident in MCREB mice.

Spine density, spine morphology, and levels of polymerized actin are unaltered in CAl neurons of naive $\mathrm{mCREB}$ mice

We first aimed at determining whether chronic inhibition of CREB function perturbs hippocampal neuronal connectivity in naive conditions. Comparison of spine counts performed on Golgi-stained CA1 neurons segments (Fig. 2A) revealed that chronic reduction of $\mathrm{CREB}$ activity did not affect the density of spines (Fig. $2 \mathrm{~B} ; F_{(1,98)}=1.68, P>0.1$ ) or the relative proportion of thin (spines smaller than $0.6 \mu \mathrm{m}$ ) (Fig. 2C; $F_{(1,69)}=0.25, P>$ 0.1 ) and large (spines larger than $0.6 \mu \mathrm{m}$ ) (Fig. $2 \mathrm{D} ; F_{(1,69)}=1.32$, $P>0.1)$ spines. The structural similarity of hippocampal morphology across genotypes was confirmed by plotting dendritic spines' head diameter in cumulative frequency curves. The two curves for WT and MCREB mice overlapped, indicating that the proportions of thin and large spines were indistinguishable between the two genotypes (Fig. 2E). Changes in spine density and morphology are mediated by the cytoskeletal protein actin, which is abundant in spines (Hotulainen and Hoogenraad 2010). Consistent with the above findings, the levels of actin in hippocampal homogenates of WT and MCREB mice were identical (Fig. $4 \mathrm{~A}$, below; $F_{(1,8)}=0.06, P>0.1$ ). Similarly, the relative levels of insoluble polymerized filamentous actin (F-actin) to soluble

monomeric actin (G-actin), reported as the F/G actin ratio, were similar in the two genotypes (Fig. 4B, below; $F_{(1,8)}=0.03, P>$ 0.1 ). These data demonstrate that chronic inhibition of CREB does not perturb basal levels of actin polymerization.

\section{mCREB expression impairs contextual fear conditioning}

We next examined the impact of chronic inhibition of CREB function on hippocampus-dependent learning. Mice were subjected to contextual fear conditioning (CFC), and their fear memory was estimated by comparing the amount of freezing during the test performed $24 \mathrm{~h}$ after training. WT and MCREB mice reported the same amount of freezing during training (Fig. 3A). During the test, however, freezing was significantly reduced in mCREB mice compared with WT mice (Fig. $3 \mathrm{~A} ; F_{(1,24)}=7.05, P<0.05$ ), confirming that loss of CREB function perturbs context conditioning in our mice. Briefly, inhibiting mCREB expression with $10 \mathrm{~d}$ of doxycycline (doxy) treatment prevented the memory impairment (Fig. 3B; $F_{(1,13)}=1.77, P>0.5$ ), demonstrating that this memory impairment was due to CREB inhibition and was reversible.

\section{A}


B All spines

\section{C} Thin spines 1
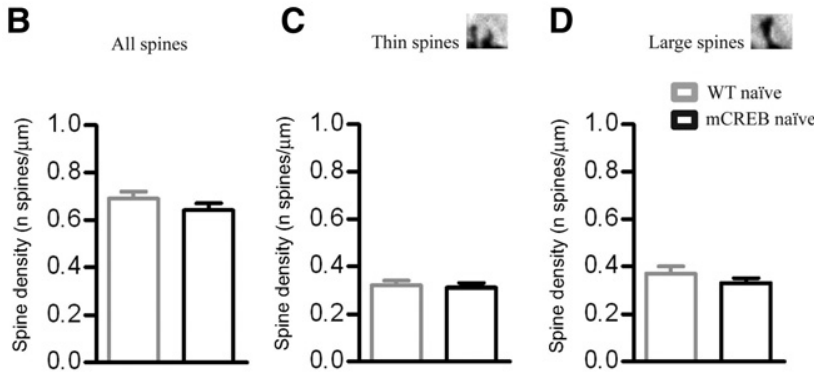

E

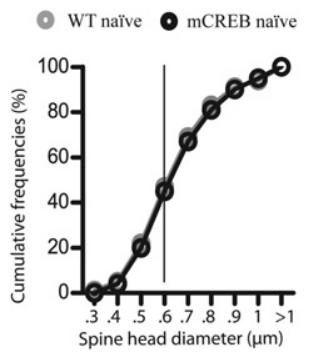

Figure 2. Blocking CREB function does not alter CA1 dendritic spine density and hippocampal actin polymerization state in naive conditions. (A) Photomicrographs of Golgi-stained hippocampal CA1 pyramidal neuron dendritic segments. Examples of stained apical dendrites are shown for naive WT and mCREB mice. Scale bar, $10 \mu \mathrm{m}$. (B) Spine density measurements along CA1 pyramidal neurons dendrites in naive WT and mCREB mice. Values are expressed as spine number (mean \pm SEM) per $1-\mu \mathrm{m}$ segment along CA1 hippocampal dendrites. Counted spines were categorized as thin $(C)$ or large $(D)$ depending on spine head diameter (thin $<0.6 \mu \mathrm{m}$, large $>0.60 \mu \mathrm{m}$ ). (E) Cumulative frequencies of head diameters values of spines with necks measured on all dendrites. $(B-E) N=$ 6 mice for each genotype; eight neurons from each mouse, 1000 spines from each group. 

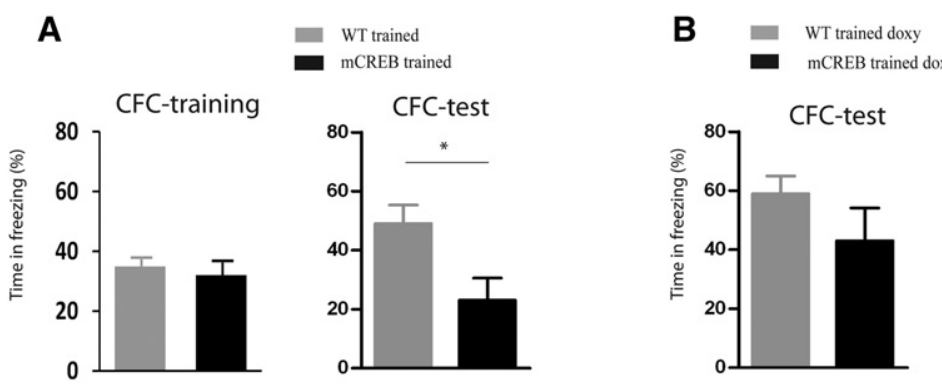

C


E

WT m $\mathrm{mCREB}$

$\mathbf{F}$

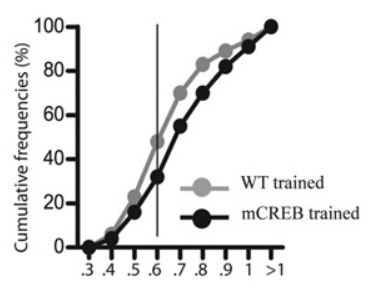

Spine head diameter $(\mu \mathrm{m}$
G

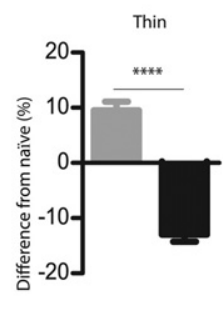

H

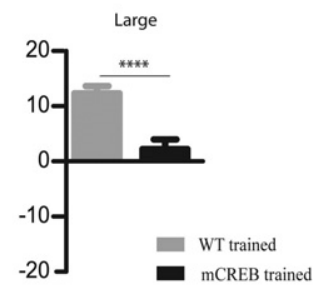

I

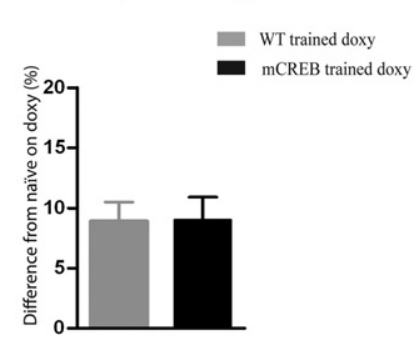

Figure 3. Effects of contextual fear conditioning (CFC) on dendritic spines and actin polymerization in WT and mCREB mice. ( $A$ ) Percentage of freezing time during the CFC training and 24-h CFC test in WT and mCREB mice off doxycycline. (B) Percentage of freezing time during 24-h CFC test in WT and mCREB mice after doxy treatment. Expression of mCREB significantly perturbs memory formation during CFC. Data are expressed as mean \pm SEM; $n$ (mice) $=14$ WT off doxy, 12 mCREB off doxy, 8 WT on doxy, 7 mCREB on doxy. (C) Photomicrograph of Golgi-stained hippocampal CA1 pyramidal neuron segments from trained WT and mCREB mice. Scale bar, $10 \mu \mathrm{m}$. (D) Spine density measurements (mean \pm SEM) in WT and mCREB mice under naive condition, $24 \mathrm{~h}$ after CFC test (trained), $24 \mathrm{~h}$ after CFC pseudo-test (pseudo-trained), or $24 \mathrm{~h}$ after shock delivery in the home cage (shock only condition). Data were averaged per neuron. $N$ neurons per group: WT naive $n=50$, mCREB naive $n=50$, WT trained $n=67$, mCREB trained $n=95$, WT pseudo $n=37$, mCREB pseudo $n=78$, WT shock only $n=48$, mCREB shock only $n=55$ from six mice analyzed per group. (E) Spine density values from WT and mCREB trained mice normalized to naive WT and mCREB conditions. $(F)$ Cumulative frequencies of head diameter values of spines with necks measured on all dendrites. $N=6$ mice for each genotype; eight neurons from each mouse, 1000 spines from each group. Spine density quantification (mean \pm SEM) of thin $(G)$ and large $(H)$ spines on dendrites from trained WT and trained mCREB mice. Bar graphs report values normalized to respective naive WT and mCREB conditions. $N=6$ mice for each group; eight neurons from each mouse, 1000 spines from each group. (I) Histograms report spine density quantification (mean \pm SEM) along all dendrites from doxy-treated trained WT and mCREB mice as percent difference from naive mice on doxy conditions. Spine densities of CA1 pyramidal neurons were similar in the naive mCREB and naive WT mice after doxy treatment $\left(F_{(1,110)}=3.03, P>0.5\right)$. Data averaged per neuron, $n=64$ neurons from $n=6$ animals analyzed per condition per genotype and normalized to doxycycline-treated naive conditions. $\left(^{*}\right) P<0.05 ;\left({ }^{* *}\right) P<0.001 ;\left({ }^{* * * *}\right) P<0.0001$.

\section{mCREB expression prevents CFC-induced large spine formation and produces CFC-induced thin spine loss}

We previously demonstrated that training C57BL/6J mice in the CFC protocol used in this study promotes a substantial increase in spine density on CA1 pyramidal neuron dendrites (Restivo et al. 2009a). We therefore investigated whether chronic inhibition of CREB function affected learning-induced spine dynamics. We measured spine density and spine head diameter in GolgiCox-stained CA1 pyramidal neuron dendrites in trained mCREB and WT mice $24 \mathrm{~h}$ after the CFC test (Fig. 3C). To ensure that this loss of spines was specific to learning and not an effect of context alone or of shock delivery, independent groups of WT and mCREB mice underwent either pseudo-training (the same behavioral protocol of training but no footshock delivery) or shock-only (mice received the same amount of footshocks in their home cage) conditions. Pseudo-trained mCREB mice showed an absence of freezing as did pseudo-trained WT mice (genotype $\times$ day interaction: $F=0.05, P=0.81$ ). As previously demonstrated, CFC elicited an increase in spine density in the WT mice (Fig. 3C,D; Restivo et al. 2009a). In contrast, CFC elicited a drastic loss of spines in mCREB mice compared with their naive controls (Fig. 
3D; genotype $\times$ group interaction: $F_{(3,472)}=16.23, P<0.0001$; WT naive vs. WT trained: $P<0.01 ;$ mCREB naive vs. MCREB trained: $P<0.001$; WT trained vs. mCREB trained: $P<0.001)$ (Fig. 3E; genotype $\times$ group interaction: $F_{(1,258)}=25.33, P<$ 0.0001 ; WT naive vs. WT trained: $P<0.01$; mCREB naive vs. mCREB trained: $P<0.001$; WT trained vs. mCREB trained: $P<$ 0.001). This opposite pattern of learning-induced spine alterations was evident in both apical and basal dendrites of CA1 pyramidal neurons (Supplemental Fig. S1A). Compared with naive mice, neither pseudo-trained $(P=0.59)$ nor shock-only mCREB mice $(P=0.20)$ exhibited any significant alterations in spine density compared with naive mice (Fig. 3D). These data demonstrate that the massive collapse of spines found in trained mCREB mice was induced by learning and is not due to non-specific factors (e.g., stress, novelty, sensorial stimulation) associated with CFC.

Since it has been suggested that thin spines are "learning spines" because fast changes in synaptic activity regulate their turnover and large spines are "memory spines" because they persist long after learning (Bourne and Harris 2007; Kasai et al. 2010), we subsequently examined whether the spine loss observed in mCREB mice upon CFC was spine-type-specific. This was evaluated by cumulative frequencies of head diameter values of spines with necks measured on all dendrites. Paradoxically, after training, a bigger proportion of large spines was found in mCREB mice than in WT mice (Fig. 3F; $P<0.001$ ). Such a shift could be caused by an increase in large spines, a relatively larger decrease in small spines, or both. This point was clarified by the following observations: In WT mice, CFC elicited an increase in the density of both thin $(P<0.001)$ and large $(P<0.001)$ spines compared with the naive condition (Fig. $3 \mathrm{G}, \mathrm{H}$ ). In mCREB mice, however, CFC produced a net loss of thin spines $(P<0.001)$ and no increase in the density of large spines compared with the naive condition $(P=0.41)$ (Fig. 3G,H). Thus, blocking CREB function in CA1 pyramidal neurons perturbs learning-dependent spine alterations in two ways. First, it results in a massive loss of thin spines, and second, it prevents the expected increase in large spines. To confirm that defective regulation of CFC-induced spine growth is specific to mCREB transgene expression, we measured spine density in mice that underwent a 10-d doxy treatment before CFC. As for CFC performance, shutting down mCREB expression reestablishes the CFC-induced spine increase in the mCREB mice (Fig. 3I; significant effect of condition: $\left.F_{(1,222)}=24.09, P<0.001\right)$.

\section{mCREB expression blocks CFC-dependent increase in actin polymerization}

Changes in spine size and shape are associated with an increased polymerization state of the cytoskeletal protein actin (Okamoto et al. 2004), and actin rearrangements have been reported in association with behavioral protocols in rodents (Hou et al. 2009). We therefore investigated whether the abnormal spine remodeling seen after CFC in mCREB mice was associated with abnormal actin cytoskeleton dynamics. Because we expected that cytoskeletal actin reorganization could contribute to dendritic spines rearrangements, we measured total actin (Fig. 4C) and the F/G actin ratio (Fig. 4D) in WT and mCREB CA1 total hippocampal protein homogenates $10 \mathrm{~min}$ after the CFC test. While total actin levels did not change after CFC, the statistical analysis performed on the $\mathrm{F} / \mathrm{G}$ actin ratio data revealed a genotype $\times$ training interaction (Fig. $4 \mathrm{~A} ; F_{(1,20)}=5.27, P<0.05$ ). In WT neurons, CFC induced an increase in the $\mathrm{F} / \mathrm{G}$ ratio (Fig. 4B; WT trained vs. naive, $P<0.05$ ), indicating actin polymerization after the CFC test. This increase, however, was absent in mCREB mice (Fig. 4B; mCREB trained vs. naive, $P=0.27$ ), resulting in a significantly lower $\mathrm{F} / \mathrm{G}$ actin ratio in mCREB mice compared with WT after the conditioning (trained WT vs. MCREB, $P<0.01$ ). This finding



Figure 4. Levels of total hippocampal actin $(A)$ or $\mathrm{F} / \mathrm{G}$-actin ratio densitometric quantification $(B)$ in WT and $\mathrm{mCREB}$ mice in naive conditions. (C) Total actin and $(D) \mathrm{F} / \mathrm{G}$ actin ratio in hippocampal extracts from WT and mCREB mice 10 min after end of the CFC test. (Top) Histograms reporting quantifications (displayed as percentage of WT naive average). (Bottom) Representative immunoblots used for quantification. (mC) mCREB. $(A, B)$ WT naive: $n=5$ mice; mCREB naive: $n=4$. $(C, D)$ WT trained: $n=5$ mice; mCREB trained: $n=6$. $\left(^{* *}\right) P<0.01$.

therefore demonstrates that CREB is necessary for learning-induced increase in actin polymerization.

\section{Discussion}

Memory formation depends on large-scale modifications in the strength and number of synaptic connections including rapid growth and elimination of dendritic spines, the postsynaptic sites of excitatory synapses. Enhancing the function of the transcription factor cAMP response element binding protein (CREB) in CA1 pyramidal neurons increases hippocampal-dependent learning (Restivo et al. 2009a; Sekeres et al. 2010; Suzuki et al. 2011) and long-term potentiation (Barco et al. 2002; Marie et al. 2005) while producing in vitro structural reorganization of neurons either in baseline conditions (Marie et al. 2005; Suzuki et al. 2007) or in relation to brief activity changes (Murphy and Segal 1997; Segal and Murphy 1998; Suzuki et al. 2007). However, whether CREB controls the homeostatic process of spine regulation and/or the structural adaptations necessary to memory formation is still undertermined. We addressed this point by investigating first whether inhibiting CREB altered the structure of hippocampal neurons in naive conditions. Our results showed that naive 
mCREB mice expressing the transgene during adulthood displayed normal hippocampal morphology, and no change in density or head diameter of spines measured in the apical and basal dendrite compartments of CA1 neurons. Consistent with these findings, the actin polymerization status of hippocampal spines was unaffected by the mutation. Our data are therefore in line with a previous report indicating that acute viral injections of dominant-negative CREB (dnCREB) do not dramatically affect baseline number and morphology of spines in visual cortex neurons since, in comparison with neurons expressing only GFP, those expressing dnCREB-GFP showed only a marginal reduction in the head size of spines with no change in spine density and length (Suzuki et al. 2007).

Conversely, subjecting mCREB mice to CFC revealed a memory impairment and disclosed structural abnormalities in CA1 neurons that did not emerge in naive conditions. As expected from previous studies (Kida et al. 2002; Mamiya et al. 2009), the mCREB mutation perturbed hippocampal-dependent contextual fear memory formation. Then, in line with our earlier report (Restivo et al. 2009b), we showed that WT mice exhibited a learning-induced increase in spine density in CA1 neurons due to the neo-formation of large and thin spines. In contrast, mCREB mice exhibited a paradoxical learning-induced decrease in spine density. This effect might be due to the concomitant absence of large spine formation and the massive loss of thin spines or, alternatively, to a massive shrinkage of all spines resulting in large spines becoming thin and thin spines being eliminated. The selective mCREB disruption of activity-dependent structural remodeling is also in good agreement with Suzuki et al. (2007), who reported that that TTX blockade of action potentials in visual cortex neurons up-regulates the amplitude of excitatory postsynaptic currents and augments spine density and spine volume in GFP neurons, while these effects are lost in dnCREB-expressing neurons. Importantly, disruption of CFC-induced structural plasticity was accompanied by a lack of learning-induced increase in actin polymerization, a cytoskeletal change that is mandatory for structural plasticity (Matus 2000; Okamoto et al. 2004; Hotulainen and Hoogenraad 2010; Rust et al. 2010), and occurred in the trained WT mice. Finally, inhibiting mCREB expression with $10 \mathrm{~d}$ of doxycycline treatment prevented the CFC impairment and restored $\mathrm{CFC}$-induced spine induction, demonstrating that defective CFC performance and spine collapse were due to loss of CREB function and were reversible.

The substantial loss of thin spines found in mCREB mice upon CFC suggests that, contrary to what happens in trained WT mice, a process of experience-dependent spine elimination is favored in the trained mutants. Evidence has accumulated in the last few years demonstrating that spines appear and disappear on a daily basis, and that the rate of this synaptic turnover is increased in response to sensory experience (Trachtenberg et al. 2002; Holtmaat et al. 2005), novelty (Kitanishi et al. 2009), seizure (Wong 2005), or memory formation (Xu et al. 2009; Yang et al. 2009). An emerging model suggests that memory is supported by reorganization of brain circuits consisting in a balance between two parallel processes governing spine formation and elimination (Kasai et al. 2010). Data from the literature indicate that this balance is regulated in vitro by LTP and LTD, which favor spine growth and elimination, respectively (Nagerl et al. 2004; Zhou et al. 2004). In light of these in vitro and our in vivo data, it is apparent that, during learning, the CREB pathway is necessary for regulating this balance in the direction of spine formation, and that disrupting its function renders the parallel process of spine elimination predominant. The observation that CREB down-regulation inverts the pattern of spine growth normally associated with fear memory consolidation suggests abnormal CREB-regulated transcription of plasticity molecules governing learning-induced rearrangements of hippocampal circuits. Candidate molecules include surface postsynaptic AMPA receptors that contribute to spine stability (Lamprecht and LeDoux 2004) by rapid translocation into the dendritic spines activated by learning (Matsuo et al. 2008) as well as the actin binding protein RhoGTPases (Cerri et al. 2011) and BDNF (von Bohlen und Halbach 2010), which is downstream from CREB activation (Carlezon et al. 2005). Thus, shutting down CREB function does not simply prevent a net increase in spines but produces spine collapse, thus pointing out that, under conditions of reduced synaptic plasticity, learning can be deleterious for neuronal connectivity.

\section{Materials and Methods}

\section{Transgenic mice}

Forebrain expression of mCREB dominant-negative mutation (serine 133 to alanine mutation) was achieved by crossing mice bearing mCREB mutation under control of the tetracyclineoperated promoter (tetOp-mCREB mouse line [Newton et al. 2002], kindly donated by R. Duman, Yale University) with mice expressing the tetracycline transactivator (tTA) under the control of the $\alpha$-calmodulin kinase II ( $\alpha$ CaMKII) promoter $(\alpha$ CaMKII-tTA mouse line [Mayford et al. 1996], Jackson Laboratories). Both lines were on a C57BL/6J mice transgenic background. Addition of doxycycline (doxy) turns off expression of mCREB. Litters were genotyped for expression of the two transgenes by PCR. To avoid abnormal development of the bi-transgenic mice, mCREB expression was prevented during development. Females were treated with food containing $40 \mathrm{mg} / \mathrm{kg}$ doxy (Bio-Serv) during the last week of pregnancy, and all litters were on this diet from birth to weaning (PND21). Upon weaning, mCREB expression was induced by removing doxy from the diet. Wild-type (WT) controls followed an identical treatment. All experiments were performed on 8- to 15-wk-old mice, allowing for several weeks of transgene expression in mCREB mice. Control data were obtained in single transgenics (44\%) and WT (56\%) littermates (both indicated as WT). Reversal experiments were performed by doxy diet administration to adult (10-11 wk old) mCREB and WT mice $10 \mathrm{~d}$ before the beginning of experiments. Mice were housed in accordance with the guidelines laid down by the European Communities Council Directive (86/609/EEC). When necessary, mice were transcardially perfused under deep anesthesia (ketamine/xylazine, 100 and $15 \mathrm{mg} / \mathrm{kg}$ ). All experiments were performed by an investigator blind to the experimental conditions of the groups. Experiments were performed under a licence issued by the Local Animal Ethics Committee (Italy; Ireland).

\section{Immunohistochemistry for Flag tag and Nissl staining} WT mice, mCREB mice under doxy treatment for 7-10 d, and mCREB mice off doxy were transcardially perfused with $4 \%$ paraformaldehyde. Brains were removed, post-fixed in paraformaldehyde overnight, cryoprotected, and sectioned frozen at $40-\mu \mathrm{m}$ thickness. Sections from three animals in each group were incubated in blocking solution (Triton $0.2 \%, 0.2 \%$ normal horse serum, $0.1 \%$ BSA, in PBS $0.1 \mathrm{M}$ ), then with mouse monoclonal antibody against Flag (1:1000; Sigma-Aldrich) for $48 \mathrm{~h}$ at $+4^{\circ} \mathrm{C}$. After incubation, sections were washed in PBS and incubated for $2 \mathrm{~h}$ at room temperature with biotinylated goat anti-rabbit secondary antibody (Vectastain; Vector Laboratories) diluted 1:600 in blocking solution. After rinsing with PBS, tissues were processed with horseradish peroxidase avidin-biotinylated complex (Vectastain; Vector Laboratories) for $1 \mathrm{~h}$ at room temperature. Sections were rinsed in PBS. The chromatic reaction was accomplished with diaminobenzidine $(50 \mathrm{mg} / 100 \mathrm{~mL}$ of PBS $)$ in the presence of $0.02 \%$ hydrogen peroxide for $6 \mathrm{~min}$. The sections were mounted on gelatin-coated slides, dehydrated through graded series of alcohols, and coverslipped with Eukitt. Sections from brains of three WT and three mCREB mice off doxy were processed for Nissl staining. Sections were stained with cresyl violet solution $(0.3 \%$ acetic acid glacial, $0.2 \%$ sodium acetate, $1 \%$ cresyl violet), 
then dehydrated through a graded series of alcohols, and coverslipped with Eukitt. Images were collected through a Leica DMLB light microscope equipped with a Moticam Pro 285A camera interfaced to a PC-based image analysis software (Motic live imaging).

Golgi Cox staining, spine density and morphology analysis Twenty-four hours after the end of the CFC test in trained and pseudo-trained mice and $48 \mathrm{~h}$ after shock delivery in shock-only conditions, brains of WT and MCREB mice were collected and processed for Golgi-Cox impregnation. Brains from naive mice were processed identically. Mice were perfused with saline, and brains were removed and impregnated in a Golgi-Cox solution (1\% potassium dichromate, $1 \%$ mercuric chloride, $0.8 \%$ potassium chromate) for $6 \mathrm{~d}$ at room temperature according to a previously described protocol (Restivo et al. 2005). Samples were immersed in a sucrose solution $(30 \%)$ for $2 \mathrm{~d}$, sectioned coronally (100 $\mu \mathrm{m}$ ) using a vibratome, and stained and mounted according to the Gibb and Kolb method (Gibb and Kolb 1998).

Images were acquired, and spine density (number of spines per 1- $\mu \mathrm{m}$ length) was estimated using the NeuroLucida software (Microbrightfields). Five 20- $\mu \mathrm{m}$ segments on secondary and tertiary branches of basal and apical dendrites from eight to 16 selected neurons from each brain were used for analysis. Images were acquired as a series of optical z-sections at $0.4-\mu \mathrm{m}$ increments to create a $\mathrm{z}$ stack of sequential images enabling segment identification, spine counting, and spine head measurements on threedimensional images. Spine density was averaged per neuron. The morphology of spines was analyzed from representative segments used for spine density analysis. Spines in which the neck was clearly evident were selected, and spine head width (distance between the edges of dendritic spine head, parallel to the dendrite) was measured using the public domain ImageJ software (NIH, USA) according to previously described protocols (Knafo et al. 2005; Middei et al. 2008). Depending on head width, spines were categorized as thin (diameter $<0.60 \mu \mathrm{m}$ ) or large $(>0.60 \mu \mathrm{m})$ (Harris et al. 1992).

\section{Western blotting}

For actin-level measurements, trained mice were sacrificed $10 \mathrm{~min}$ after the end of the test phase of CFC, and hippocampi were collected for Western blotting. Naive WT and mCREB mice were processed identically. Actin-level measurements were performed with some modifications from the protocol described by Fukazawa et al. (2003). Briefly, hippocampi were homogenized at $4^{\circ} \mathrm{C}$ in lysis buffer (1\% Triton X-100, $50 \mathrm{mM}$ Tris at pH 7.5, $100 \mathrm{mM} \mathrm{NaCl}$, $1 \mathrm{mM}$ sodium orthovanadate, $50 \mathrm{mM} \mathrm{NaF}$, protease inhibitor cocktail [Sigma-Aldrich]) and centrifuged at $1000 \mathrm{~g}$ for $10 \mathrm{~min}$. Half of the supernatant was collected to determine the total actin amount. The rest was spun at $10,000 \mathrm{~g}$ for $20 \mathrm{~min}$, and the supernatant, containing the detergent-soluble cell fraction (G-actin), was collected. Pellets containing the insoluble fraction (F-actin) were dissolved in RIPA buffer from Sigma-Aldrich, Italy (1\% Triton X-100, $150 \mathrm{mM} \mathrm{NaCl}, 1.0 \%$ IGEPAL CA-630, 0.5\% sodium deoxycholate, $0.1 \%$ SDS, $50 \mathrm{mM}$ Tris at $\mathrm{pH} 8.0,10 \mathrm{mM}$ EDTA, $1 \mathrm{mM}$ DTT) for $3 \mathrm{~h}$ at $4^{\circ} \mathrm{C}$. The total, soluble, and insoluble fractions were run on $4 \%-12 \%$ SDS-PAGE gels in equal amounts. Immuno-detection was performed using an anti-actin antibody (1:7000 dilution; Sigma-Aldrich). Immuno-reactivity was detected using the HRP-coupled anti-IgG antibody and visualized with the ECLplus enhance chemiluminescence kit (Amersham Biosciences). Bands were visualized with the Storm Scanner Control and analyzed using the Quantity one basic software (Bio-Rad).

\section{Contextual fear conditioning}

Mice were handled in the experimental room for $3 \mathrm{~d}$. On the fourth day, they were trained in the conditioning chamber (square cage: dimensions $28 \times 28 \mathrm{~cm}$ with transparent walls). Training consisted in 2 min of habituation before the delivery of 5 footshocks $(0.7 \mathrm{~mA}, 2 \mathrm{sec})$ at 1-min intervals. One minute after the last footshock, mice returned to their home cage. A group of mice underwent pseudo-training, consisting in putting mice for $7 \mathrm{~min}$ in the conditioning chamber without the delivery of footshocks. Context conditioning was assessed $24 \mathrm{~h}$ after the training or pseudo-training by placing mice for $5 \mathrm{~min}$ in the conditioning chamber. Mouse behavior was videotaped, and fear memory was manually assessed by scoring the total amount of freezing behavior (defined as complete lack of movement, except for respiration) during the 5-min test. Values are reported as percent of time spent freezing. A group of mice underwent the shock-only condition in the animal room. Mice were first placed in a cage similar to their home cage in which a grid floor for shock delivery was inserted. They received five footshocks $(0.7 \mathrm{~mA}, 2 \mathrm{sec})$ within $90 \mathrm{sec}$ with inter-shock intervals variable between 10 and $30 \mathrm{sec}$. At the end of the procedure, mice returned to their home cage. Brains were collected $48 \mathrm{~h}$ after the shock delivery to conform to the time delay between shock delivery and brain collection for the CFC condition.

\section{Statistical analysis}

All studies were performed by experimenters blind to the genotypes and experimental conditions of the animals. Spine density raw data among mice in naive, training, pseudo-training, and shock-only conditions were evaluated by means of two-way ANOVA with Genotype and Condition as between factors. Relative proportions of thin and large spines, total actin, and $\mathrm{F} / \mathrm{G}$ actin values from mice examined in naive conditions were compared among groups by means of a One-Way ANOVA with Genotype as between factor. Cumulative frequencies of spine head diameters were compared by Kolmogorov-Smirnov tests. CFC performance was expressed as the percent of freezing during test and compared among genotypes by means of a One-Way ANOVA. Spine density values in trained animals normalized to naive, total actin, and $\mathrm{F} / \mathrm{G}$ actin values collected after training mice in CFC were compared among groups including the data collected on naive animals by means of a Two-Way ANOVA with Genotype and Condition as between factors. Newman-Keuls post hoc tests were then used for pair comparisons where necessary. All differences were considered significant for $P<0.05$.

\section{Acknowledgments}

This work was supported by the Irish Research Council for Science, Engineering and Technology, Ireland (to S.M., S.M.O.), Regione Lazio "Sviluppo della Ricerca sul Cervello" (to M.A.-T.), and the Italian Institute of Technology (to H.M.). S.M. thanks Alyson Reynolds (U.C.D., Ireland) for assistance with the mouse colony and Annabella Pignataro for work on dendritic spines. We also thank Ronald Duman (Yale University) for sharing the mCREB transgenic mice, Cristina Marchetti (EBRI, Italy), and Angel Barco (Neuroscience Institute, UMH-Alicante, Spain) for insightful discussions and comments on the manuscript.

Authors' contributions: S.M. performed and analyzed the immunohistochemistry, behavior, and spine analysis experiments. S.M. also bred and genotyped the mice. A.S. and P.L. performed and analyzed the actin measurements. S.M.O. and C.P. provided initial inputs to the project and advice during experimental design and preparation of manuscript. H.M. and M.A.-T. supervised design, analysis, and interpretation of all experiments. H.M., M.A.-T. and S.M. wrote the manuscript.

\section{References}

Barco A, Marie H. 2011. Genetic approaches to investigate the role of CREB in neuronal plasticity and memory. Mol Neurobiol 44: 330-349.

Barco A, Alarcon JM, Kandel ER. 2002. Expression of constitutively active CREB protein facilitates the late phase of long-term potentiation by enhancing synaptic capture. Cell 108: 689-703.

Bourne J, Harris KM. 2007. Do thin spines learn to be mushroom spines that remember? Curr Opin Neurobiol 17: 381-386.

Carlezon WA, Duman RS, Nestler EJ. 2005. The many faces of CREB. Trends Neurosci 28: 436-445. 
Cerri C, Fabbri A, Vannini E, Spolidoro M, Costa M, Maffei L, Fiorentini C, Caleo M. 2011. Activation of Rho GTPases triggers structural remodeling and functional plasticity in the adult rat visual cortex. J Neurosci 31: 15163-15172.

Fukazawa Y, Saitoh Y, Ozawa F, Ohta Y, Mizuno K, Inokuchi K. 2003. Hippocampal LTP is accompanied by enhanced F-actin content within the dendritic spine that is essential for late LTP maintenance in vivo. Neuron 38: 447-460.

Gibb R, Kolb B. 1998. A method for vibratome sectioning of Golgi-Cox stained whole rat brain. J Neurosci Methods 79: 1-4.

Harris KM, Jensen FE, Tsao B. 1992. Three-dimensional structure of dendritic spines and synapses in rat hippocampus (CA1) at postnatal day 15 and adult ages: Implications for the maturation of synaptic physiology and long-term potentiation. J Neurosci 12: $2685-2705$.

Holtmaat AJ, Trachtenberg JT, Wilbrecht L, Shepherd GM, Zhang X, Knott GW, Svoboda K. 2005. Transient and persistent dendritic spines in the neocortex in vivo. Neuron 45: 279-291.

Hotulainen P, Hoogenraad CC. 2010. Actin in dendritic spines: Connecting dynamics to function. J Cell Biol 189: 619-629.

Hou YY, Lu B, Li M, Liu Y, Chen J, Chi Z-Q, Liu JG. 2009. Involvement of actin rearrangements within the amygdala and the dorsal hippocampus in aversive memories of drug withdrawal in acute morphine-dependent rats. J Neurosci 29: 12244-12254

Kasai H, Fukuda M, Watanabe S, Hayashi-Takagi A, Noguchi J. 2010. Structural dynamics of dendritic spines in memory and cognition. Trends Neurosci 33: 121-129.

Kida S, Josselyn SA, Pena DO, Kogan JH, Chevere I, Masushige S, Silva AJ. 2002. CREB required for the stability of new and reactivated fear memories. Nat Neurosci 5: 348-355.

Kitanishi T, Ikegaya Y, Matsuki N, Yamada MK. 2009. Experiencedependent, rapid structural changes in hippocampal pyramidal cell spines. Cereb Cortex 11: 2572-2578.

Knafo S, Ariav G, Barkai E, Libersat F. 2004. Olfactory learning-induced increase in spine density along the apical dendrites of CA1 hippocampal neurons. Hippocampus 14: 819-825.

Knafo S, Libersat F, Barkai E. 2005. Olfactory learning-induced morphological modifications in single dendritic spines of young rats. Eur J Neurosci 21: 2217-2226.

Lamprecht R, LeDoux J. 2004. Structural plasticity and memory. Nat Rev Neurosci 5: 45-54.

Leuner B, Falduto J, Shors TJ. 2003. Associative memory formation increases the observation of dendritic spines in the hippocampus. J Neurosci 23: 659-665.

Mamiya N, Fukushima H, Suzuki A, Matsuyama Z, Homma S, Frankland PW, Kida S. 2009. Brain region-specific gene expression activation required for reconsolidation and extinction of contextual fear memory. J Neurosci 29: 402-413.

Marie H, Morishita W, Yu X, Calakos N, Malenka RC. 2005. Generation of silent synapses by acute in vivo expression of CaMKIV and CREB. Neuron 45: 741-752.

Matsuo N, Reijmers L, Mayford M. 2008. Spine-type-specific recruitment of newly synthesized AMPA receptors with learning. Science 319: 1104-1107.

Matus A. 2000. Actin-based plasticity in dendritic spines. Science 290: $754-$ 758.

Mayford M, Bach ME, Huang YY, Wang L, Hawkins RD, Kandel ER. 1996. Control of memory formation through regulated expression of a CaMKII transgene. Science 274: 1678-1683.

Middei S, Restivo L, Caprioli A, Aceti M, Ammassari-Teule M. 2008. Region-specific changes in the microanatomy of single dendritic spines over time might account for selective memory alterations in ageing hAPPsweTg2576 mice, a mouse model for Alzheimer disease. Neurobiol Learn Mem 90: 467-471.

Murphy DD, Segal M. 1997. Morphological plasticity of dendritic spines in central neurons is mediated by activation of cAMP response element binding protein. Proc Natl Acad Sci 94: 1482-1487.
Nagerl UV, Eberhorn N, Cambridge SB, Bonhoeffer T. 2004. Bidirectional activity-dependent morphological plasticity in hippocampal neurons. Neuron 44: $759-767$.

Newton SS, Thome J, Wallace TL, Shirayama Y, Schlesinger L, Sakai N, Chen J, Neve R, Nestler EJ, Duman RS. 2002. Inhibition of cAMP response element-binding protein or dynorphin in the nucleus accumbens produces an antidepressant-like effect. J Neurosci 22: 10883-10890.

Okamoto K, Nagai T, Miyawaki A, Hayashi Y. 2004. Rapid and persistent modulation of actin dynamics regulates postsynaptic reorganization underlying bidirectional plasticity. Nat Neurosci 7: 1104-1112.

O'Malley A, O'Connell C, Regan CM. 1998. Ultrastructural analysis reveals avoidance conditioning to induce a transient increase in hippocampal dentate spine density in the 6 hour post-training period of consolidation. Neuroscience 87: 607-613.

Restivo L, Ferrari F, Passino E, Sgobio C, Bock J, Oostra BA, Bagni C, Ammassari-Teule M. 2005. Enriched environment promotes behavioral and morphological recovery in a mouse model for the fragile $\mathrm{X}$ syndrome. Proc Natl Acad Sci 102: 11557-11562.

Restivo L, Roman FS, Ammassari-Teule M, Marchetti E. 2006. Simultaneous olfactory discrimination elicits a strain-specific increase in dendritic spines in the hippocampus of inbred mice. Hippocampus 16: 472-479.

Restivo L, Vetere G, Bontempi B, Ammassari-Teule M. 2009a. The formation of recent and remote memory is associated with time-dependent formation of dendritic spines in the hippocampus and anterior cingulate cortex. J Neurosci 29: 8206-8214.

Restivo L, Tafi E, Ammassari-Teule M, Marie H. 2009b. Viral-mediated expression of a constitutively active form of CREB in hippocampal neurons increases memory. Hippocampus 19: 228-234.

Rust MB, Gurniak CB, Renner M, Vara H, Morando L, Gorlich A, Sassoe-Pognetto M, Banchaabouchi MA, Giustetto M, Triller A, et al. 2010. Learning, AMPA receptor mobility and synaptic plasticity depend on n-cofilin-mediated actin dynamics. EMBO J 29: 1889-1902.

Segal M, Murphy DD. 1998. CREB activation mediates plasticity in cultured hippocampal neurons. Neural Plast 6: 1-7.

Sekeres MJ, Neve RL, Frankland PW, Josselyn SA. 2010. Dorsal hippocampal CREB is both necessary and sufficient for spatial memory. Learn Mem 17: $280-283$.

Suzuki S, Zhou H, Neumaier JF, Pham TA. 2007. Opposing functions of CREB and MKK1 synergistically regulate the geometry of dendritic spines in visual cortex. J Comp Neurol 503: 605-617.

Suzuki A, Fukushima H, Mukawa T, Toyoda H, Wu LJ, Zhao MG, Xu H, Shang Y, Endoh K, Iwamoto T, et al. 2011. Upregulation of CREBmediated transcription enhances both short- and long-term memory. J Neurosci 31: 8786-8802.

Trachtenberg JT, Chen BE, Knott GW, Feng G, Sanes JR, Welker E, Svoboda K. 2002. Long-term in vivo imaging of experience-dependent synaptic plasticity in adult cortex. Nature 420: 788-794.

Tronson NC, Wiseman SL, Neve RL, Nestler EJ, Olausson P, Taylor JR. 2012. Distinctive roles for amygdalar CREB in reconsolidation and extinction of fear memory. Learn Mem 19: 178-181.

von Bohlen und Halbach O. 2010. Involvement of BDNF in age-dependent alterations in the hippocampus. Front Aging Neurosci 2: 36. doi: 10.3389 /fnagi.2010.00036.

Wong S. 2005. Modulation of dendritic spines in epilepsy: Cellular mechanisms and functional implications. Epilepsy Behav 7: 569-577.

Xu T, Yu X, Perlik AJ, Tobin WF, Zweig JA, Tennant K, Jones T, Zuo Y. 2009. Rapid formation and selective stabilization of synapses for enduring motor memories. Nature 462: 915-919.

Yang G, Pan F, Gan WB. 2009. Stably maintained dendritic spines are associated with lifelong memories. Nature 462: 920-924.

Zhou Q, Homma KJ, Poo MM. 2004. Shrinkage of dendritic spines associated with long-term depression of hippocampal synapses. Neuron 44: $749-757$.

Received January 27, 2012; accepted in revised form May 7, 2012. 




\section{CREB selectively controls learning-induced structural remodeling of neurons}

Silvia Middei, Alida Spalloni, Patrizia Longone, et al.

Learn. Mem. 2012, 19:

Access the most recent version at doi:10.1101//m.025817.112

\section{Supplemental http://learnmem.cshlp.org/content/suppl/2012/07/18/19.8.330.DC1 Material}

References This article cites 45 articles, 16 of which can be accessed free at: http://learnmem.cshlp.org/content/19/8/330.full.html\#ref-list-1

\section{License}
Email Alerting Receive free email alerts when new articles cite this article - sign up in the box at the Service top right corner of the article or click here.

